\title{
Electrochemical Push-Pull Probe: From Scanning Electrochemical Microscopy to Multimodal Altering of Cell Microenvironment
}

\author{
Alexandra Bondarenko, ${ }^{\dagger}$ Fernando Cortés-Salazar, ${ }^{\dagger}$ Mihaela Gheorghiu, ${ }^{\ddagger}$ Szilveszter Gáspár, ${ }^{\ddagger}$ \\ Dmitry Momotenko, ${ }^{\dagger}$ Luciana Stanica, ${ }^{\ddagger, \S}$ Andreas Lesch, ${ }^{\dagger}$ Eugen Gheorghiu, ${ }^{\ddagger}{ }^{\ddagger}$ and Hubert H. Girault ${ }^{*}, \dagger$ \\ ${ }^{\dagger}$ Laboratoire d’Electrochimie Physique et Analytique, École Polytechnique Fédérale de Lausanne, CH-1015 Lausanne, Switzerland \\ ${ }^{\ddagger}$ International Centre of Biodynamics, 1B Intrarea Portocalelor Street, 060101 Bucharest, Romania \\ ${ }^{\S}$ Faculty of Biology, University of Bucharest, 91-95 Splaiul Independentei, 050095 Bucharest, Romania
}

Supporting Information

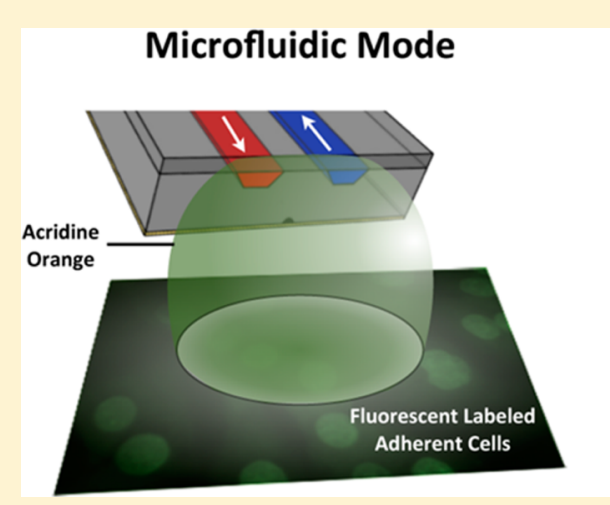

\section{Electrochemical Mode}

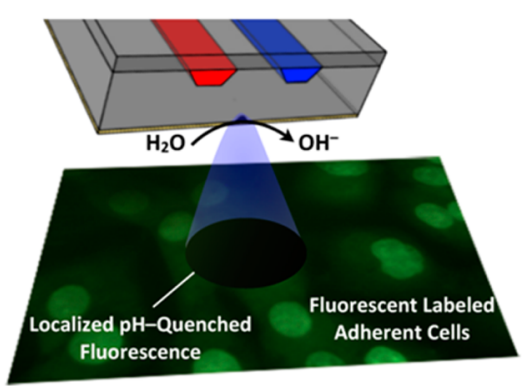

ABSTRACT: To understand biological processes at the cellular level, a general approach is to alter the cells' environment and to study their chemical responses. Herein, we present the implementation of an electrochemical push-pull probe, which combines a microfluidic system with a microelectrode, as a tool for locally altering the microenvironment of few adherent living cells by working in two different perturbation modes, namely electrochemical (i.e., electrochemical generation of a chemical effector compound) and microfluidic (i.e., infusion of a chemical effector compound from the pushing microchannel, while simultaneously aspirating it through the pulling channel, thereby focusing the flow between the channels). The effect of several parameters such as flow rate, working distance, and probe inclination angle on the affected area of adherently growing cells was investigated both theoretically and experimentally. As a proof of concept, localized fluorescent labeling and $\mathrm{pH}$ changes were purposely introduced to validate the probe as a tool for studying adherent cancer cells through the control over the chemical composition of the extracellular space with high spatiotemporal resolution. A very good agreement between experimental and simulated results showed that the electrochemical perturbation mode enables to affect precisely only a few living cells localized in a high-density cell culture.

$\mathrm{E}$ ssential cellular behaviors such as proliferation, apoptosis, toxicity, cytokinesis, chemotaxis, asymmetric cell division, or changes in synaptic strength are hallmark processes that require well-orchestrated, spatially localized, and dynamic biochemical strategies. Typically, investigating biochemical changes requires (i) the manipulation of cells in a fixed volume space, (ii) the perturbation of the system by introducing an external agent (e.g., drug) or a new condition (e.g., $\mathrm{pH}$ or temperature), and (iii) the detection of the cell response. Despite all the optical imaging techniques that can reveal within a minute details of living cells' interior, ${ }^{1-4}$ it remains challenging to image and modify simultaneously the chemical environment around cells with a high sensitivity and resolution. ${ }^{1}$ Microfabrication techniques opened new ways of studying biological processes by providing devices with capacities for growing, seeding, or sorting cells and by providing microfluidic networks for controlling the extracellular environ- ment, in a manner either fully compatible with or capable of integrating various current powerful detection techniques. ${ }^{5-9}$ For instance, multipurpose scanning microfluidic probes ${ }^{10,11}$ were suggested for the local assessment and perturbation of cellular environments. Similarly, new microfluidic probes consisting of three open microchannels, ${ }^{12-14}$ two for aspirating and one for infusing, were introduced for single-cell manipulations to analyze the enzymatic activity of kinase and house-keeping proteins present in a single cell extract. ${ }^{13}$

Scanning electrochemical microscopy (SECM) is an analytical technique for characterization of chemical surface reactivity and topography based on the collection of an electrochemical signal at an ultramicroelectrode (UME), which

Received: February 3, 2015

Accepted: April 2, 2015

Published: April 2, 2015 
is scanned over a specimen in the presence of an electrolyte solution. ${ }^{15}$ Thanks to its high spatial resolution and versatility, SECM has allowed nanoscale electrochemical imaging of single human breast epithelial cells as well as accessing intracellular media in order to measure the rate of transmembrane transport, membrane potential, or simply probing redox properties of the intracellular space. ${ }^{16-20}$ Therefore, several SECM studies of mammalian living cells, such as HeLa cells, ${ }^{21-25}$ breast cancer cells, hepatocytes, ${ }^{26}$ human liver cells, ${ }^{26}$ human erythroleukemia cells, ${ }^{27}$ mouse embryonic stem cells, ${ }^{28}$ human neutrophils, ${ }^{29}$ and human prostate cancer cells ${ }^{30}$ have been reported. Furthermore, by combining SECM with other analytical techniques such as optical microscopy (SECM-OM), shear force distance regulation, or scanning ion conductive microscopy (SICM), it has been made possible to extract additional useful chemical or topographic information on living cells. $^{31-33}$

While most SECM experiments are devoted to the "reading" of adherent cells, the perturbation of the cell environment through electrochemical reactions can also be implemented as shown by Bergner et al. ${ }^{34}$ While this task seems to be complicated for classic glass-encapsulated UMEs, it can be easily solved by employing the soft polymeric probes initially developed to carry out SECM experiments on tilted, rough, and large surfaces in a contact mode. ${ }^{35-41}$ Indeed, these probes can be combined with microfluidics to release locally electrolyte solutions in the gap between the sensing UME and the sample area under study, as in case of the fountain pen ${ }^{42}$ or additionally to aspirate the delivered solution, as in case of the microfluidic push-pull probe. ${ }^{43}$ As a result, the readout of surface reactivity at metal-on-glass structures, human fingerprints, immobilized enzymes, and self-assembled monolayers has been demonstrated. $^{42-44}$ Furthermore, the electrochemical push-pull scanner (the modified version of the microfluidic push-pull probe) has enabled the coupling of SECM with mass spectrometry for the extraction of chemical and electrochemical surface information. ${ }^{44}$ Finally, because of their softness, the soft probes proved to be ideal for scanning delicate substrates, such as self-assembled monolayers. ${ }^{40}$

Herein, we introduced the electrochemical push-pull probe and characterized the new electrochemical push-pull probe as a precise perturbation tool for adherent cancer cells in a dual electrochemical and microfluidic mode. More specifically, the control of the chemical composition of the extracellular space is achieved by using a microfluidic mode (i.e., the infusion of a chemical effector from the pushing microchannel, while aspirating it through the pulling channel) and/or an electrochemical mode (i.e., the electrochemical generation of a chemical effector). As a proof of concept, fluorescent labeling of adherently growing cancer cells in the microfluidic mode and their response under a locally induced $\mathrm{pH}$ change in the electrochemical mode were demonstrated. Finite element analysis of coupled Navier-Stokes and diffusion-convection differential equations showed good agreement with the experimental data, confirming the unique dual electrochemical push-pull probe capabilities as a writing tool of biological samples.

\section{EXPERIMENTAL SECTION}

Chemicals. Acridine orange hydrochloride hydrate (AO), 4(2-hydroxyethyl)piperazine-1-ethanesulfonic acid (HEPES), ferrocene methanol $\left(\mathrm{FcCH}_{2} \mathrm{OH}, \geq 97 \%\right)$, sodium chloride, and sodium hydroxide were purchased from Sigma-Aldrich
(Munich, Germany). All chemical reagents were of analytical grade and were used without further purification. Ultrapure water (Milli-Q) was used as a solvent.

Cell Culture Preparation. A549 cells (human lung cancer cell line) were grown on Dulbecco's modified Eagle's medium (DMEM) supplemented with $10 \%$ fetal bovine serum (FBS) and penicillin-streptomycin $(100 \mathrm{IU} / \mathrm{mL})$ at $37{ }^{\circ} \mathrm{C}$ in a $5 \%$ $\mathrm{CO}_{2}$ humidified incubator (Sanyo). Cells were split at $70 \%$ confluence using Trypsin-EDTA (0.5\%) and seeded in glassbottomed cell culture dishes (World Precision Instruments) at a concentration of $1.8 \times 10^{5}$ cells $/ \mathrm{mL}$ and grown to $80 \%$ confluency prior to experiments in DMEM. All culture media and supplements were purchased from Gibco/Invitrogen.

Before the experiments, the adherent cells were washed, and the growth medium was replaced with Ringer solution that includes $130 \mathrm{mM} \mathrm{NaCl}, 1 \mathrm{mM} \mathrm{KCl}, 1 \mathrm{mM} \mathrm{MgCl}, 2 \mathrm{mM}$ $\mathrm{CaCl}_{2}, 10 \mathrm{mM}$ HEPES, and $10 \mathrm{mM}$ glucose ( $\mathrm{pH} 7.4$, adjusted with $\mathrm{NaOH}$ ). The cell line was chosen on the basis of its good resilience to environmental perturbations, in order to avoid nonspecific cellular changes during the operations with the electrochemical push-pull probe.

Electrochemical Push-Pull Probe Fabrication. The electrochemical push-pull probe was manufactured by UVphotoablation of $100 \mu \mathrm{m}$ thick polyethylene terephthalate substrate (PET, MelinexDupont, Wilmington, DE, USA), using a $193 \mathrm{~nm}$ ArF excimer laser beam (Lambda Physik, Gottingen, Germany, frequency $=50 \mathrm{~Hz}$, energy $=350 \mathrm{~mJ}$ ) as it has been reported previously. ${ }^{36,43}$ Briefly, two parallel microchannels (100 $\mu \mathrm{m}$ width, $30 \mu \mathrm{m}$ depth, $60 \mu \mathrm{m}$ distance between channels) were fabricated on one side of a PET film. A third parallel microchannel ( $30 \mu \mathrm{m}$ width, $20 \mu \mathrm{m}$ depth) was ablated in-between the previous two channels but on the opposite side of the PET film. The latter microchannel was manually filled with a carbon ink (Electra Polymer and Chemicals Ltd., Roughway Mill, Dunk Green, England) and cured at $80{ }^{\circ} \mathrm{C}$ for $1 \mathrm{~h}$ to create a carbon UME. Furthermore, the side with two open microchannels was laminated with a polyethylene (PE)/ PET film (Payne, Wildmere Road, Banbury, England) to create two microfluidic channels. Thereafter, the UME was coated by a $2 \mu \mathrm{m}$ thick Parylene $\mathrm{C}$ film, using a parylene deposition system (Comelec SA, La Chaux-de-Fonds, Switzerland). Before each experiment, the probe was cut manually with a surgical scalpel blade to obtain a fresh electrode surface and a V-shaped tip $(0.5-2 \mathrm{~mm}$ wide). The electrochemical response of the carbon microelectrode was verified by cyclic voltammetry in a solution of $2 \mathrm{mM} \mathrm{FcCH} \mathrm{FH}_{2} \mathrm{OH} 0.1 \mathrm{M} \mathrm{KNO}_{3}$ and $10 \mathrm{mM}$ HEPES (see Supporting Information Section SI-I).

Computational Model and Numerical Simulations. To estimate the size and the shape of the areas affected by the electrochemical push-pull probe operating in the microfluidic and electrochemical modes, finite element analysis of coupled Navier-Stokes and diffusion-convection differential equations in steady-state conditions were carried out in a manner similar to that reported previously. ${ }^{43}$ The computational model of the probe assumes that the probe (parallel-piped with dimensions $=$ $125 \mu \mathrm{m}$ thickness $\times 500 \mu \mathrm{m}$ width $\times 1000 \mu \mathrm{m}$ height $)$ in a boxshaped domain $(2000 \mu \mathrm{m}$ length $\times 2000 \mu \mathrm{m}$ width $\times(1000+$ $d \mu \mathrm{m}$ ) height, where $d$ is the distance between the probe and the substrate) that represents the bulk solution (Figure 1a,b). The active area of the UME was approximated to a half-disc shape with a $20 \mu \mathrm{m}$ radius, and the simulated microchannels had the shape of an isosceles trapezium located in the opposite side of the probe (i.e., 70 and $100 \mu \mathrm{m}$ base length, $30 \mu \mathrm{m}$ 


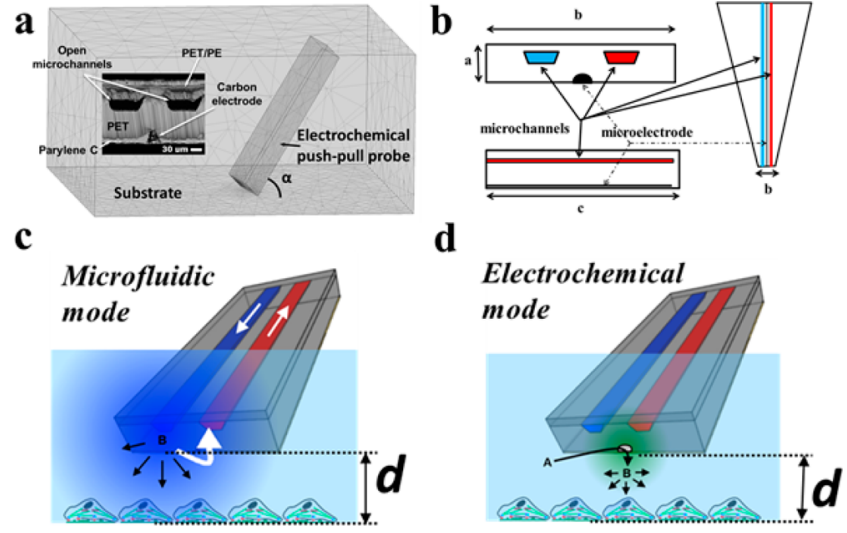

Figure 1. (a) Grid for the numerical simulations of the area affected by the electrochemical push-pull probe when it is positioned above the substrate at an inclination angle $\alpha$ at the working distance $d$. Inset shows a microscopic cross-sectional image of the probe. (b) Schematic representation (with dimensions) of the electrochemical push-pull probe. Illustrations of the (c) microfluidic focusing mode and (d) the electrochemical mode for the localized perturbation of living cells are also presented.

height, and center-to-center separation of $160 \mu \mathrm{m}$, Figure 1a). When the finite element analysis is employed, one important factor to be considered is the mesh size. Here, the NavierStokes equation was solved with a fine mesh size between $10^{-5}$ and $10^{-6} \mathrm{~m}$ at the substrate plane, the microchannels, and the electrode edge, which corresponds to the most relevant regions in the present system. To optimize the calculation time, the mesh employed to map the bulk solution was on the range of $7.5 \times 10^{-5} \mathrm{~m}$, which still allows a precise characterization of the convection-diffusion process within the simulated system. It is important to notice that the above-mentioned mesh sizes were found to be the optimum ones after carrying out several simulations with different mesh sizes and obtaining a reproducible and mesh-independent solution to the system. Numerical simulations were carried out for both microfluidic and electrochemical operation modes at different flow rates, inclination angles $\left(\alpha=90\right.$ or $\left.70^{\circ}\right)$ and working distances $(d)$ between the tip and the substrate surface (Figure 1b,c). The two inclination angles employed for the simulation correspond to the most common experimental conditions under which the electrochemical push-pull probe is used for SECM experiments. ${ }^{43}$ For instance, working with an inclination angle of $70^{\circ}$ allows an easier positioning of the probe in a closer proximity to the substrate without scratching adherent cells. In contrast, working at $90^{\circ}$ assures a more oriented perturbation. In each case, the affected substrate area was determined on the basis of the concentration profile of a given chemical effector B (which can perturb cells in different manners) delivered from an open microchannel or electrochemically generated from a nonactive compound A (which cannot perturb cells) at the microelectrode and transported to the substrate surface by diffusion only. All simulations were run by using an initial normalized concentration of $\mathrm{B}$ and $\mathrm{A}$ equal to unity for microfluidic and electrochemical modes, respectively. ImageJ software (Wayne Rasband, Research Services Branch, National Institute of Mental Health, Bethesda, Maryland, USA) was employed to determine the whole affected area in each case. Furthermore, to corroborate that the employed set of equations was solved appropriately, the well-known wall-jet electrode (WJE) system $^{45}$ was solved numerically and compared with the analytical solution. (For more details, see Supporting Information Section SI-II,)

Local Perturbation of Adherent Cells. For each experiment, a Petri dish containing adherently growing cancer cells was positioned on top of an AxioObserver Z1 inverted microscope (Zeiss, Germany) combined with an XYZ positioning system (consisting of a DC-3K micromanipulator and an STM 3 controller from MärzhäuserWetzlar GmbH \& Co. KG). The electrochemical push-pull probe was mounted on a homemade plexiglass holder with a predefined inclination angle of 70 or $90^{\circ}$ and fixed on the above-mentioned positioning system. The microchannels were connected to a computercontrolled syringe pump (Cavro XLP 6000 from Tecan Systems, Inc.) and valve (Model M6 liquid handling pump from VICI AG International) through silica capillaries (TSP FS-Tubing, $100 \mu \mathrm{m}$ inner diameter (ID), $363 \mu \mathrm{m}$ outer diameter (OD) from BGB Analytik AG, Switzerland) and fittings (NanoPort Assemblies from IDEX Health \& Science LLC, USA). The positioning of the probe over the adherent cancer cells at a working distance (e.g., 2.5, 50, 100, or $250 \mu \mathrm{m}$ ) was verified by using the optical focusing of the inverted microscope. Specifically, the objective of the microscope was focused on the cells surface and its absolute position was recorded. Thereafter, the objective was moved up by a defined value equivalent to the desired working distance (e.g., 2.5, 50, 100 , or $250 \mu \mathrm{m}$ ) and the electrochemical push-pull probe was moved down until the plane of the microelectrode and the open microchannels were in the focus of the objective. Furthermore, the objective was refocused on the cell surface to confirm the working distance value. Then, the probe was employed to affect the cell culture by using one of the operating modes. For instance, in the microfluidic mode, cancer cells were labeled by fluorescent $\mathrm{AO}$ species delivered from the electrochemical push-pull probe at a nominal pushing flow rate of $1 \mu \mathrm{L} / \mathrm{min}$ (during $2 \mathrm{~min}$ ) and a nominal aspirating flow rate of 0,20 , or $50 \mu \mathrm{L} / \mathrm{min}$. The final image of the cell surface after perturbation was obtained by employing a band-pass filter for excitation (BP 450-490 nm) and a long-pass filter (>515 $\mathrm{nm}$ ) for emission, in conjunction with the monochromatic iXon DU-885 K EMCCD camera from Andor and analyzed by Image J software in order to determine the affected area (on the basis of the pixel size, calculated taking into account all magnifications). A similar procedure was followed to determine the area of the cell-covered surface affected by the electrochemical push-pull probe operated in the electrochemical mode. In such cases, the probe was positioned above adherent cells previously labeled with $\mathrm{AO}$ and a constant potential of -2 $\mathrm{V}$ was applied at the UME (vs an Ag quasi-reference electrode, Ag-QRE) for a given time by using an Autolab potentiostat (Autolab PGSTAT101, MetrohmAutolab B.V., The Netherlands). This procedure induced a drastic increase of the local $\mathrm{pH}$ value, which decreased the fluorescence in the cells at the detection wavelength (vide infra). The electrochemical operation mode was further employed to generate a Morse code S-O-S signal (i.e., three short signals, or dots, for S, three long signals, or dashes, for $\mathrm{O}$, followed by three short signals for $S$ ) by purposely controlling the fluorescence intensity of adherent cells. With this aim, the probe was positioned $7 \mu \mathrm{m}$ above the cell-covered surface with an inclination angle of $70^{\circ}$ and the following potential step program was applied: a potential of $-2 \mathrm{~V}$ was applied during 30 $s$ to generate the dots, whereas the dash lines were generated by biasing the electrode at $-2 \mathrm{~V}$ during $60 \mathrm{~s}$. A potential of $0 \mathrm{~V}$ 
was applied for $60 \mathrm{~s}$ in between dots and dashes and for $120 \mathrm{~s}$ in between characters. The Ag-QRE electrode was additionally characterized versus standard $\mathrm{Ag} / \mathrm{AgCl} / 3 \mathrm{M} \mathrm{KCl}$ electrode.

Additionally, a $10 \mathrm{mM} \mathrm{NaOH}$ solution was delivered over AO-labeled cells to confirm that changes in the fluorescence, observed while using the electrochemical push-pull probe in the electrochemical operation mode, were caused by local $\mathrm{pH}$ changes. The $\mathrm{NaOH}$ solution was consequently delivered over the fluorescent AO-labeled cells with a flow rate equal to 0.5 $\mu \mathrm{L} / \mathrm{min}$ over $50 \mathrm{~s}$.

\section{RESULTS AND DISCUSSION}

Computational Model and Numerical Simulations. Microfluidic Mode. To estimate theoretically the area affected by the electrochemical push-pull probe operated in the microfluidic mode (Figure 1b), the computational model assumed a probe positioned with an inclination angle of 90 or $70^{\circ}$ at a distance of 50,100 , or $250 \mu \mathrm{m}$ above the substrate. Furthermore, a chemical effector $\mathrm{B}$ was delivered through the pushing channel with a flow rate equal to $1 \mu \mathrm{L} / \mathrm{min}$, whereas the aspirating flow rate was varied from 0 to $10 \mu \mathrm{L} / \mathrm{min}$. The system of Navier-Stokes and diffusion-convection equations was then solved to estimate the influence of the inclination angle, probe-substrate distance, and aspirating flow rate on the sample affected area (Supporting Information Section SI-III).

The results of the numerical simulations demonstrated the significant influence of the aspirating rate on the affected area (Figure 2 and Supporting Information Section SI-III). Implementing the aspiration focuses the flow of the chemical effector B delivered by the electrochemical push-pull probe. Indeed, the affected areas shown in Figure 2 have a shape of an elongated oval that is sharpened on the side of the pulling

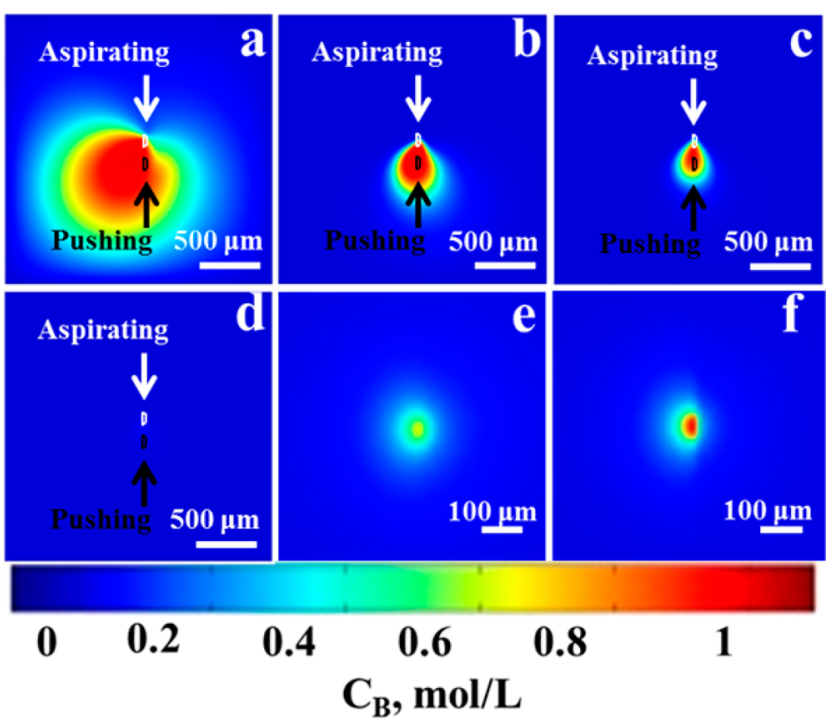

Figure 2. Concentration profiles of the active compound B delivered over the sample surface by the electrochemical push-pull probe operated in $(a-d)$ microfluidic and $(e-f)$ electrochemical modes under different conditions. For the microfluidic mode for all the simulations, the pushing flow rate was $1 \mu \mathrm{L} / \mathrm{min}$ and the inclination angle was $70^{\circ}$. Aspirating flow rate and the working distance $d$ were, respectively, (a) $1 \mu \mathrm{L} / \mathrm{min}$ and $50 \mu \mathrm{m}$, (b) $5 \mu \mathrm{L} / \mathrm{min}$ and $50 \mu \mathrm{m}$, (c) 5 $\mu \mathrm{L} / \mathrm{min}$ and $100 \mu \mathrm{m}$, and (d) $5 \mu \mathrm{L} / \mathrm{min}$ and $250 \mu \mathrm{m}$. For the electrochemical mode, the inclination angle was equal to $70^{\circ}$ and the working distance $d$ was (e) $15 \mu \mathrm{m}$ and (f) $2 \mu \mathrm{m}$. microchannel. Varying the value of the pulling flow rate changes the shape of the global concentration gradients, which is reflected on the affected area. For instance, increasing the pulling flow rate from 1 to $5 \mu \mathrm{L} / \mathrm{min}$ for the $70^{\circ}$ inclination angle and $50 \mu \mathrm{m}$ working distance decreases the affected area drastically from ca. $2 \times 10^{6}$ to $4.5 \times 10^{5} \mu \mathrm{m}^{2}$ (Figure 2a,b, respectively). The influence of the working distance on the affected area is more significant at high aspirating flow rates. For instance, with a $5 \mu \mathrm{L} / \mathrm{min}$ aspirating flow rate, the increase of the working distance from 50 to $100 \mu \mathrm{m}$ generates a decrease of the affected area by about three-fold (Figure 2c, sample affected area ca. $\left.1.5 \times 10^{5} \mu \mathrm{m}^{2}\right)$. As expected, the subsequent increase of the working distance up to $250 \mu \mathrm{m}$ leads to the further decrease of the concentration of the active compound $\mathrm{B}$ on the substrate (Figure 2d, less than $10 \%$ from the initial concentration of $\mathrm{B}$ reaches the surface). In contrast, when the aspirating flow rate is equal to $1 \mu \mathrm{L} / \mathrm{min}$, the affected area is very similar for all working distances (see Supporting Information Section SI-III). Moreover, changing the inclination angle from 70 to $90^{\circ}$ generates slightly wider affected areas with a behavior similar to that observed when the working distance was constant (for more details, see Supporting Information Section SI-III).

Electrochemical Mode. The electrochemical operation mode of the probe (Figure 1c) is based on the in situ electrochemical generation of species that can perturb adherent cells locally. The computational model in this case assumes that the nonactive compound A present in the solution is converted into the chemical effector $B$ at the UME, which then diffuses to the substrate. As in the previous case, the probe was positioned with an inclination angle of 90 or $70^{\circ}$ but at working distances from 2 to $25 \mu \mathrm{m}$ above the substrate. For the numerical simulations, a fast reaction rate constant for the conversion of $\mathrm{A}$ into $\mathrm{B}$ was assumed (i.e., $k=10^{6} \mathrm{~m} \mathrm{~s}^{-1}$, for more details, see Supporting Information Section SI-IV).

As in the case of the microfluidic operation mode, a similar behavior was observed when the working distance was varied for both inclination angles; therefore, only the results obtained with the $70^{\circ}$ inclination angle will be further discussed (for more details, see Supporting Information Section SI-IV). Indeed, the working distance has a significant influence on the concentration profile of the active compound $\mathrm{B}$ over the substrate and on the whole affected area. For example, increasing $d$ from 2 to $15 \mu \mathrm{m}$ decreases the maximum concentration of $\mathrm{B}$ that reaches the substrate from 1 to 0.46 $\mathrm{M}$ (Figure 2e,f). Accordingly, the whole affected area increases from $10^{4}$ to $4 \times 10^{4} \mu \mathrm{m}^{2}$ because of the broader diffusion field generated, but the area affected with a concentration of active compound higher than $95 \%$ is approximately $70 \mu \mathrm{m}^{2}$, which coincides to the size of a single or a few living cells. Furthermore, the affected area for the same working distance is smaller when the probe is positioned with an inclination angle equal to $70^{\circ}$, as compared to the case when this angle is $90^{\circ}$. The latter is mainly due to the diffusion profiles that is developed toward the sample plane in comparison with an angle equal to $90^{\circ}$ (Supporting Information Section SI-IV).

Experimental Perturbation of Adherent Cancer Cells. Microfluidic Mode. The electrochemical push-pull probe was used in the microfluidic mode to label adherent A549 cancer cells with $\mathrm{AO}$. AO is a fluorescent dye that has found wide application in cellular biology because of its capability to penetrate cell membranes and bind both DNA and RNA. ${ }^{46}$ Because A549 cancer cells do not have an intrinsic fluorescence, 
only the adherent cells that capture $\mathrm{AO}$ will be clearly highlighted in the fluorescence image. With this aim, a solution of AO ( $0.002 \%$ in Ringer buffer) was delivered by using the electrochemical push-pull probe in order to study the influence of different parameters (e.g., working distance, inclination angle, and aspiration rate) on the affected cell area. For each experiment, $\mathrm{AO}$ was only delivered during the first $2 \mathrm{~min}$, whereas the aspiration rate was kept constant for the complete duration of the experiment (i.e., $10 \mathrm{~min}$ ). To avoid any interference from the autofluorescence of the probe materials (i.e., PET and PE, see Supporting Information Section SI-V), the probe was moved away from the field of view of the microscope before the final image of the perturbed cells was obtained. A period of $8 \mathrm{~min}$ between stopping the pushing channel and taking the final image was necessary to prevent additional cell staining when moving away the probe. The latter was required to avoid any perturbation because of the convection generated by the probe repositioning and the pressure remaining in the microfluidic system even after the pump was turned off (Supporting Information Section SI-V).

The most representative results for the perturbation of cells by the electrochemical push-pull probe operating in a microfluidic mode are presented in Figure 3. When the probe
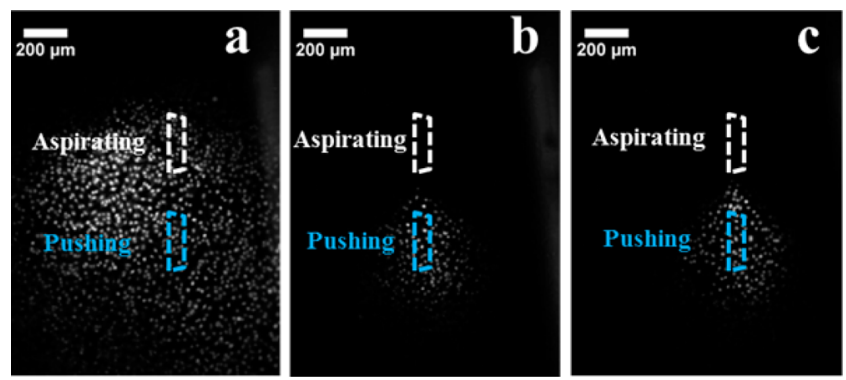

Figure 3. Fluorescence microscopy images of adherent cancer cells affected by the electrochemical push-pull probe operated in a microfluidic mode with an inclination angle of $90^{\circ}$. Blue and white dashed lines represent the position of the pushing and aspirating microchannels, respectively. Nominal pushing flow rate was $1 \mu \mathrm{L} / \mathrm{min}$ and the nominal aspirating flow rate and the working distance $d$ were, respectively, (a) $0 \mu \mathrm{L} / \mathrm{min}$ and $50 \mu \mathrm{m}$, (b) $20 \mu \mathrm{L} / \mathrm{min}$ and $50 \mu \mathrm{m}$, and (c) $50 \mu \mathrm{L} / \mathrm{min}$ and $50 \mu \mathrm{m}$.

is employed without aspiration, the dimension of the affected area is defined mainly by the time of the assay ( $2 \mathrm{~min}$ in the present case). For instance, when $\mathrm{AO}$ was delivered at a working distance of $50 \mu \mathrm{m}$ and with an inclination angle of $90^{\circ}$, the area of the affected cells occupied almost the entire field of view of the microscope (i.e., square millimeter scale, Figure 3a). By carrying out the same experiment but with a nominal aspiration flow rate of $20 \mu \mathrm{L} / \mathrm{min}$, the labeled area presented a deformed oval shape, which was sharpened below the location of the aspirating microchannel (Figure 3b). Moreover, the affected area in this case corresponds to approximately $3.1 \times$ $10^{5} \mu \mathrm{m}^{2}$, which was reached and kept almost constant after a period of $60 \mathrm{~s}$ of injection, thanks to the achievement of steadystate conditions (see Supporting Information Sections SI-V and SI-VI). To investigate whether the efficiency of the aspirating microchannel can be further improved, a higher pulling flow rate was also employed while labeling cells with AO (i.e., 50 $\mu \mathrm{L} / \mathrm{min}$, Figure $3 \mathrm{c}$ ). However, no significant differences compared to the previous experiments were observed (Figure $3 b, c)$. This confirms that a maximum effective aspiration rate was already achieved at the nominal pulling flow rate of $20 \mu \mathrm{L} /$ min. Indeed, depending on the microchannel dimensions, the presence of air bubbles in the microchannels, and the dead volumes of the microfluidic connections, the effective aspiration rate does not necessarily correspond to the nominal one (i.e., effective aspiration rate $<$ nominal aspiration rate).

As predicted from the numerical simulations, changing the inclination angle from 90 to $70^{\circ}$ does not introduce significant differences (see Figure 2 and Supporting Information Sections SI-III and SI-VI). However, for a $50 \mu \mathrm{m}$ working distance, a larger and wider oval area was obtained for a $70^{\circ}$ inclination angle (i.e., $6.7 \times 10^{5} \mu \mathrm{m}^{2}$ for $70^{\circ}$ compared to $3.3 \times 10^{5} \mu \mathrm{m}^{2}$ for $90^{\circ}$, see Figure 4a). This result can be explained mainly by

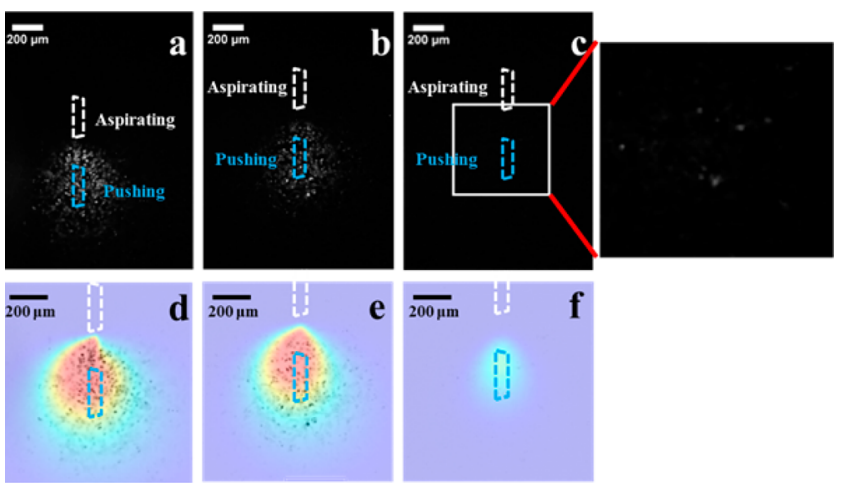

Figure 4. $(a-c)$ Fluorescence microscopy images of cancer cells labeled with $\mathrm{AO}$ (white spots) by the electrochemical push-pull probe operated in a microfluidic mode with an inclination angle of $70^{\circ}$. (d-f) Overlapping between the numerically simulated affected area (color image) and the experimental results (presented as inverted black and white images; labeled cells are depicted as black spots). Blue and white dashed lines represent the position of the pushing and aspirating microchannels, respectively. Experimental nominal aspirating flow rate was $20 \mu \mathrm{L} / \mathrm{min}$, whereas the one used for the simulations was $3 \mu \mathrm{L} /$ min. Working distance $d$ was $50 \mu \mathrm{m}$ for a and $\mathrm{d}, 100 \mu \mathrm{m}$ for b and e, and $250 \mu \mathrm{m}$ for $\mathrm{c}$ and $\mathrm{f}$. The pushing flow rate was $1 \mu \mathrm{L} / \mathrm{min}$ for all experiments.

the differences on the effective aspiration flow rates achieved in each experiment. By comparing the experimental results obtained with the electrochemical push-pull probe at different working distances (Figure $4 a-c)$ and the simulated results obtained under similar conditions (e.g., inclination angle of $70^{\circ}$ ), it can be suggested that the effective aspiration rate achieved experimentally is approximately equal to $3 \mu \mathrm{L} / \mathrm{min}$ (Figure $4 \mathrm{~d}-\mathrm{f}$ ), whereas for $90^{\circ}$ it was close to $10 \mu \mathrm{L} / \mathrm{min}$ (Supporting Information Section SI-VI).

The behavior observed experimentally in terms of shape and size of the affected area correlates qualitatively with the numerical results, especially for the effects caused by the working distance and inclination angle. Further increase of $d$ up to $100 \mu \mathrm{m}$ (with a $70^{\circ}$ inclination angle) only introduces slight changes on the shape (i.e., sharpened oval shape) and size (i.e., $5.3 \times 10^{5} \mu \mathrm{m}^{2}$ ) of the affected area (Figure $4 \mathrm{~b}$ ). However, when a working distance of $250 \mu \mathrm{m}$ was employed, the size and the intensity of the labeled area were drastically reduced (Figure 4c). Despite the fact that only few stained cells with very low fluorescence intensity can be observed on the final image, the labeling of cells under these conditions corresponds more to a random distribution (see also Figure 4f).

Electrochemical Mode. One of the possibilities to affect adherent cells electrochemically using the electrochemical 
push-pull probe is to change locally the $\mathrm{pH}$ of the extracellular space, for instance by carrying out the electrolysis of water at the integrated carbon UME. Moreover, local $\mathrm{pH}$ changes can be monitored optically by taking advantage of the $\mathrm{pH}$ dependence of the AO fluorescence. The fluorescence of $\mathrm{AO}$ loaded into cells presents a red shift when the $\mathrm{pH}$ of the media is increased or decreased. ${ }^{47-49}$ Indeed, Figure S10 in Supporting Information Section SI-VII shows the quenching of the $\mathrm{AO}$ fluorescence by a local $\mathrm{pH}$ change when a solution of $\mathrm{NaOH}$ (i.e., $0.01 \mathrm{M}$, flow rate $=0.6 \mu \mathrm{L} / \mathrm{min}$ during $50 \mathrm{~s}$ ) is delivered over fluorescent AO-labeled cells. The decrease of the fluorescence intensity was followed by a recovery on the edge of the affected area only, whereas for the cells located just below the $\mathrm{NaOH}$ delivery zone, slight or negligible recovery was observed most likely because of the longer exposure to a high $\mathrm{NaOH}$ concentration that can irreversibly affect the $\mathrm{pH}$ cell status (Supporting Information Section SI-VII). All these observations are in good agreement with the use of $\mathrm{AO}$ as a $\mathrm{pH}$ indicator within the cellular environment. ${ }^{47-49}$ Thus, if the $\mathrm{UME}$ of the probe is biased to a potential of $-2 \mathrm{~V}$, then a local $\mathrm{pH}$ increase will be induced because of $\mathrm{OH}^{-}$generation $\left(2 \mathrm{H}_{2} \mathrm{O}\right.$ $\left.+2 \mathrm{e}^{-} \rightarrow \mathrm{H}_{2}+2 \mathrm{OH}^{-}\right)$. This can then be monitored by the quenching of $\mathrm{AO}$ fluorescence of the labeled cells. As shown by Cannan et al., drastic $\mathrm{pH}$ changes (i.e., between 3 to $6 \mathrm{pH}$ units) can be observed in the vicinities of an electrode where the consumption of $\mathrm{H}^{+}$(or generation of $\mathrm{OH}^{-}$) is taking place. ${ }^{50}$ In our specific case, it was expected to observe similar but slightly compressed $\mathrm{pH}$ profiles caused by the presence of the Ringer buffer that acts as a chemical lens to constrain the localized $\mathrm{pH}$ change. ${ }^{51}$ Additionally, it is important to note that when applying $-2 \mathrm{~V}$ at the microelectrode not only water reduction but also oxygen reduction can take place (for more details, see Supporting Information Section SI-I). This process can locally decrease the concentration of the dissolved oxygen, which can lead to apoptosis and possible morphological changes of adherent cells. However, no morphological marks of cell apoptosis were detected during the experiment. Probably, oxygen diffusion was fast enough and the time during which the local oxygen concentration was influenced by the probe was short enough not to affect irreversibly the live cells.

The affected area can be thus determined by the decrease of the fluorescence intensity of AO-labeled cells. With this aim, after the electrochemical push-pull probe was employed to label the adherent cells with AO, it was brought in a close proximity of the cells (e.g., from a working distance of $20 \mu \mathrm{m}$ to a working distance of $2.5 \mu \mathrm{m}$ ), and a potential of $-2 \mathrm{~V}$ was applied for $180 \mathrm{~s}$. The applied potential allowed a perturbation of AO-labeled adherent cells, without generation of $\mathrm{H}_{2}$ bubbles. The latter was confirmed optically by the inverted microscope and by the stable current profiles recorded during the applied potential steps.

The experimental results obtained for the perturbation of adherent cells with the electrochemical push-pull probe operating in an electrochemical mode with an inclination angle of $70^{\circ}$ are shown in Figure 5. Similar results were obtained when using the probe with an inclination angle of $90^{\circ}$ (see Supporting Information Section SI-VIII). However, an easier and therefore closer positioning of the probe over the cell surface was achieved when using the probe with an inclination angle of $70^{\circ}$ (because aligning an edge of the probe to the cells is easier than aligning the whole cross section). As it can be seen in Figure $5 \mathrm{a}, \mathrm{b}$, when operating the probe at a working

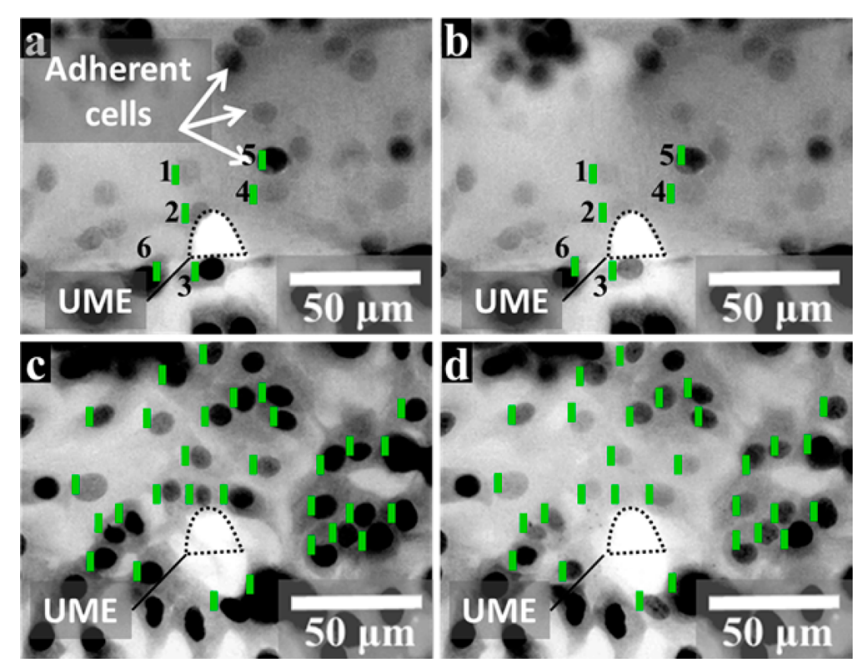

Figure 5. Fluorescence microscopy images (a and c) before and (b and d) after the perturbation of adherent cancer cells labeled with $\mathrm{AO}$ by using the electrochemical push-pull probe in an electrochemical mode. For a better visualization, all obtained images were converted into black and white, the colors were inverted, and the brightness adjusted. Working distance $d$ was $2.5 \mu \mathrm{m}$ for a and b and $15 \mu \mathrm{m}$ for c and $\mathrm{d}$; the inclination angle was equal to $70^{\circ}$. Working electrode, integrated carbon paste UME; QRE, Ag; CE, Pt; applied potential = $-2 \mathrm{~V}$. Cells marked with green were significantly affected during the experiment.

distance of $2.5 \mu \mathrm{m}$, only few cells (i.e., 6 cells, sample affected area $\approx 9000 \mu \mathrm{m}^{2}$ ) present a decrease of their fluorescent intensity. However, only the adherent cancer cells located just below the microelectrode present a drastic decrease of their AO fluorescence intensity (Movie 1, Supporting Information). As discussed previously, the electrochemical operation mode might enable affecting areas as small as $70 \mu \mathrm{m}^{2}$ with localized concentration profiles of up to $95 \%$ of the maximum reachable concentration of an electrogenerated compound. The latter results demonstrate the capabilities of the electrochemical push-pull probe for the precise and localized perturbation of living cells in an electrochemical operation mode. As expected, with the increase of the working distance, an increase of the affected area is observed (Figure 5c,d). For instance, when increasing the working distance to $15 \mu \mathrm{m}$, approximately 30 cells are clearly affected, corresponding to an area equal to $2 \times$ $10^{4} \mu \mathrm{m}^{2}$. The dependency of the affected areas on the working distance can be interpreted in terms of the different extension of the truncated diffusion fields created between the probe and the substrate. Thus, a smaller distance between the probe and the substrate will generate a smaller perturbation area. The latter is in a very good agreement with the numerical simulations, where similar behavior was observed for both inclination angles (Figure 2 and Supporting Information Section SI-IV). Moreover, the numerical results reproduced qualitatively the truncated round shape of the affected areas caused by the probe position and inclination. Indeed, in Figure $5 \mathrm{a}$, cell 3 , just below the edge of the UME, is not drastically affected because the diffusion of electrogenerated species is also truncated in this direction.

It is important to note that after the applied voltage was switched off, the fluorescence intensity of the AO species inside the affected cells was substantially recovered. The latter suggests the possibility to perform reversible (temporal) cell perturbations by working in an electrochemical mode that in 
addition can be precisely localized in a small number of cells (spatially). To demonstrate the dynamic perturbation provided by the electrochemical push-pull probe operating in an electrochemical mode, a Morse code $\mathrm{S}-\mathrm{O}-\mathrm{S}$ signal was generated by applying a potential step program to induce local $\mathrm{pH}$ changes over AO-labeled cells (Experimental Section). A video (Movie 2, Supporting Information) shows the possibility to control precisely and in a reversible way the intracellular $\mathrm{pH}$ and thus the intensity of the intracellular fluorescence given by AO. The recorded video was further analyzed using ImageJ software to read the fluorescence intensity profile of the cells positioned under the UME as a function of time (Figure 6 and

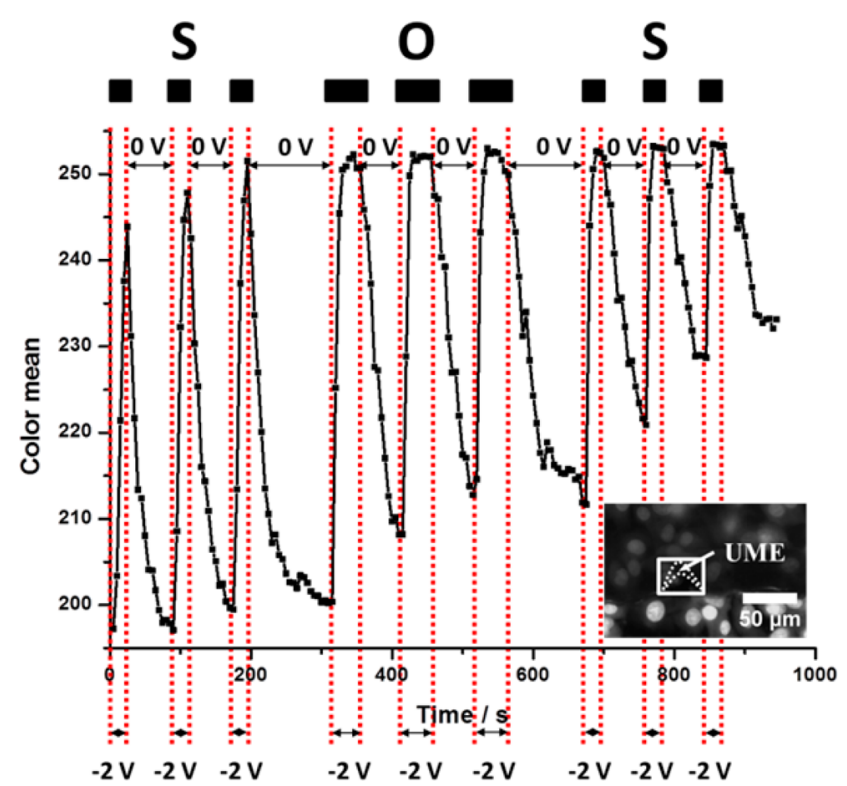

Figure 6. Reversed fluorescence intensity profile of the AO-labeled cells during the electrochemically induced Morse code $\mathrm{S}-\mathrm{O}-\mathrm{S}$ signal. Working electrode, integrated carbon paste UME; QRE, Ag; CE, Pt; applied potential $=-2 \mathrm{~V}$; working distance $d=10 \mu \mathrm{m}$. Inset: microscopic image of AO-labeled adherent cells with the electrochemical push-pull probe positioned above them. White square within the inset shows the area of which fluorescence intensity was analyzed.

inset of the same). The first and the last three peaks of the image correspond to the three dots that generate the $S$ letter in Morse code. The next three broader peaks stand for the three dashes that generate the letter $\mathrm{O}$. The results of the experiments showed good reproducibility of the signal during the first three cycles; however starting from the sixth cycle, a significant decrease of the fluorescence was observed. The latter is most likely due to the long exposure of the cells to a considerable concentration of $\mathrm{OH}^{-}$that can affect drastically the cell status and does not allow the fluorescence to recover completely before the next potential pulse is applied (i.e., -2 $\mathrm{V})$, as was also observed when delivering $\mathrm{NaOH}$ through the probe (Supporting Information Section SI-VII).

\section{CONCLUSIONS}

We demonstrated the precise spatiotemporal perturbation of adherent living cells by taking advantage of the integrated electrochemical and microfluidic modes inside a soft electrochemical push-pull probe. Numerical simulations of the implemented probe and the influence of different parameters, such as aspiration rate, working distance, and probe inclination angle, indicated the possibility to perturb only few cells via the electrochemical mode and a group of a few hundred cells by using the microfluidic mode. The latter possibility was thoroughly verified experimentally. With this aim, localized fluorescent labeling of adherently growing cells was achieved by flowing AO out from one of the open microchannels while pulling it into the other open microchannel. Furthermore, highly localized $\mathrm{pH}$ changes were induced by the integrated microelectrode in areas covering only few cells. Finally, the capability of our system for localized, dynamic, and reversible cell perturbation was illustrated with a cell-emitted $\mathrm{S}-\mathrm{O}-\mathrm{S}$ signal obtained by purposely tuning the fluorescent intensity of AO-labeled cells via electrochemically induced spatiotemporal $\mathrm{pH}$ changes. This study paves the way for further applications of multiparametric cell stimulation to study $\mathrm{pH}$ influence on the growth and proliferation of malignant cancer cells as well as to analyze the samples collected from the extracellular space through the pulling channel.

Moreover, the developed soft electrochemical push-pull probe can be used for imaging. Work is in progress to image cells, alter them, and visualize electrochemically the effects of the alteration.

\section{ASSOCIATED CONTENT}

\section{S Supporting Information}

Electrochemical characterization of the electrochemical pushpull probe, numerical simulations of the probe operated in a microfluidic and an electrochemical mode, and results for the experimental perturbation of cancer adherent cells in a microfluidic and electrochemical operating mode, including two videos. This material is available free of charge via the Internet at http://pubs.acs.org.

\section{AUTHOR INFORMATION}

\section{Corresponding Author}

*E-mail: hubert.girault@epfl.ch. Tel.: +41-21-693-3145. Fax: +41-21-693-3667.

\section{Notes}

The authors declare no competing financial interest.

\section{ACKNOWLEDGMENTS}

The authors are thankful to the SNSF from Switzerland and the UEFISCDI from Romania for their support through the joint project no. IZERZO_142236/1.

\section{REFERENCES}

(1) Toomre, D.; Bewersdorf, J. Annu. Rev. Cell Dev. Biol. 2010, 26, 285-314.

(2) Lang, P.; Yeow, K.; Nichols, A.; Scheer, A. Nat. Rev. Drug Discovery 2006, 5, 343-356.

(3) Fletcher, J. S. Analyst 2009, 134, 2204-2215.

(4) Bulte, J. W. M.; Kraitchman, D. L. NMR Biomed. 2004, 17, 484499.

(5) Servant, G.; Weiner, O. D.; Herzmark, P.; Balla, T.; Sedat, J. W.; Bourne, H. R. Science 2000, 287, 1037-1040.

(6) Kim, B. J.; Wu, M. Ann. Biomed. Eng. 2012, 40, 1316-1327.

(7) Cimetta, E.; Figallo, E.; Cannizzaro, C.; Elvassore, N.; VunjakNovakovic, G. Methods 2009, 47, 81-89.

(8) Torisawa, Y.-S.; Kaya, T.; Takii, Y.; Oyamatsu, D.; Nishizawa, M.; Matsue, T. Anal. Chem. 2003, 75, 2154-2158.

(9) Taylor, R. J.; Falconnet, D.; Niemistö, A.; Ramsey, S. A.; Prinz, S.; Shmulevich, I.; Galitski, T.; Hansen, C. L. Proc. Natl. Acad. Sci. U.S.A. 2009, 106, 3758-3763. 
(10) Juncker, D.; Schmid, H.; Delamarche, E. Nat. Mater. 2005, 4, 622-628.

(11) Kaigala, G. V.; Lovchik, R. D.; Drechsler, U.; Delamarche, E. Langmuir 2011, 27, 5686-5693.

(12) Ainla, A.; Jeffries, G. D. M.; Brune, R; Orwar, O.; Jesorka, A. Lab Chip 2012, 12, 1255-1261.

(13) Sarkar, A.; Kolitz, S.; Lauffenburger, D. A.; Han, J. Nat. Commun. 2014, 5, 3421.

(14) Ainla, A.; Gözen, I.; Hakonen, B.; Jesorka, A. Sci. Rep. 2013, 3, 2743.

(15) Amemiya, S.; Bard, A. J.; Fan, F.-R. F.; Mirkin, M. V.; Unwin, P. R. Annu. Rev. Anal. Chem. 2008, 1, 95-131.

(16) Amemiya, S.; Guo, J.; Xiong, H.; Gross, D. A. Anal. Bioanal. Chem. 2006, 386, 458-471.

(17) Bergner, S.; Vatsyayan, P.; Matysik, F.-M. Anal. Chim. Acta 2013, 775, 1-13.

(18) Liu, B.; Rotenberg, S. A.; Mirkin, M. V. Proc. Natl. Acad. Sci. U.S.A. 2000, 97, 9855-9860.

(19) Sun, P.; Laforge, F. O.; Abeyweera, T. P.; Rotenberg, S. A.; Carpino, J.; Mirkin, M. V. Proc. Natl. Acad. Sci. U.S.A. 2008, 105, 443448.

(20) Roberts, W. S.; Lonsdale, D. J.; Griffiths, J.; Higson, S. P. J. Biosens. Bioelectron. 2007, 23, 301-318.

(21) Chen, Z.; Xie, S.; Shen, L.; Du, Y.; He, S.; Li, Q.; Liang, Z.; Meng, X.; Li, B.; Xu, X.; Ma, H.; Huang, Y.; Shao, Y. Analyst 2008, 133, 1221-1228.

(22) Li, X.; Bard, A. J. J. Electroanal. Chem. 2009, 628, 35-42.

(23) Koley, D.; Bard, A. J. Proc. Natl. Acad. Sci. U.S.A. 2012, 109, $11522-11527$

(24) Kuss, S.; Polcari, D.; Geissler, M.; Brassard, D.; Mauzeroll, J. Proc. Natl. Acad. Sci. U.S.A. 2013, 110, 9249-9254.

(25) Kuss, S.; Kuss, C.; Trinh, D.; Schougaard, S. B.; Mauzeroll, J. Electrochim. Acta 2013, 110, 42-48.

(26) Mauzeroll, J.; Bard, A. J.; Owhadian, O.; Monks, T. J. Proc. Natl. Acad. Sci. U.S.A. 2004, 101, $17582-17587$.

(27) Torisawa, Y.-S.; Kaya, T.; Takii, Y.; Oyamatsu, D.; Nishizawa, M.; Matsue, T. Anal. Chem. 2003, 75, 2154-2158.

(28) Matsumae, Y.; Arai, T.; Takahashi, Y.; Ino, K.; Shiku, H.; Matsue, T. Chem. Commun. (Cambridge, U.K.) 2013, 49, 6498-6500.

(29) Gao, N.; Wang, X.; Li, L.; Zhang, X.; Jin, W. Analyst 2007, 132, $1139-1146$.

(30) Salamifar, S. E.; Lai, R. Y. Anal. Chem. 2013, 85, 9417-9421.

(31) Takahashi, Y.; Shiku, H.; Murata, T.; Yasukawa, T.; Matsue, T. Anal. Chem. 2009, 81, 9674-9681.

(32) Takahashi, Y.; Shevchuk, A. I.; Novak, P.; Murakami, Y.; Shiku, H.; Korchev, Y. E.; Matsue, T. J. Am. Chem. Soc. 2010, 132, 1011810126.

(33) Takahashi, Y.; Shevchuk, A. I.; Novak, P.; Zhang, Y.; Ebejer, N.; Macpherson, J. V.; Unwin, P. R.; Pollard, A. J.; Roy, D.; Clifford, C. A.; Shiku, H.; Matsue, T.; Klenerman, D.; Korchev, Y. E. Angew. Chem., Int. Ed. 2011, 50, 9638-9642.

(34) Bergner, S.; Wegener, J.; Matysik, F. M. Anal. Chem. 2011, 83, $169-174$.

(35) Kranz, C. Analyst 2014, 139, 336-352.

(36) Cortés-Salazar, F.; Trauble, M.; Li, F.; Busnel, J.; Gassner, A.; Hojeij, M.; Wittstock, G.; Girault, H. H. Anal. Biochem. 2009, 81, 6889-6896.

(37) Cortés-Salazar, F.; Momotenko, D.; Lesch, A.; Wittstock, G.; Girault, H. H. Anal. Chem. 2010, 82, 10037-10044.

(38) Cortés-Salazar, F.; Momotenko, D.; Girault, H. H.; Lesch, A.; Wittstock, G. Anal. Chem. 2011, 83, 1493-1499.

(39) Lesch, A.; Momotenko, D.; Cortés-Salazar, F.; Wirth, I.; Tefashe, U. M.; Meiners, F.; Vaske, B.; Girault, H. H.; Wittstock, G. J. Electroanal. Chem. 2012, 666, 52-61.

(40) Lesch, A.; Vaske, B.; Meiners, F.; Momotenko, D.; CortésSalazar, F.; Girault, H. H.; Wittstock, G. Angew. Chem., Int. Ed. 2012, 51, 10413-10416.

(41) Lesch, A.; Momotenko, D.; Cortés-Salazar, F.; Roelfs, F.; Girault, H. H.; Wittstock, G. Electrochim. Acta 2013, 110, 30-41.
(42) Cortés-Salazar, F.; Lesch, A.; Momotenko, D.; Busnel, J.-M.; Wittstock, G.; Girault, H. H. Anal. Methods 2010, 2, 817.

(43) Momotenko, D.; Cortes-Salazar, F.; Lesch, A.; Wittstock, G.; Girault, H. H. Anal. Chem. 2011, 83, 5275-5282.

(44) Momotenko, D.; Qiao, L.; Cortés-Salazar, F.; Lesch, A.; Wittstock, G.; Girault, H. H. Anal. Chem. 2012, 84, 6630-6637.

(45) Compton, R. G.; Greaves, C. R.; Waller, A. M. J. Appl. Electrochem. 1990, 20, 586-589.

(46) Zoccarato, F.; Cavallini, L.; Alexandre, A. J. Neurochem. 1999, 72, 625-633.

(47) Kapuscinski, J.; Darzynkiewicz, Z. J. Biomol. Struct. Dyn. 1987, 5, 127-143.

(48) Lyles, M. B.; Cameron, I. L. Biophys. Chem. 2002, 96, 53-76.

(49) Han, J.; Burgess, K. Chem. Rev. 2010, 110, 2709-2728.

(50) Cannan, S.; Douglas Macklam, I.; Unwin, P. R. Electrochem. Commun. 2002, 4, 886-892.

(51) Borgwarth, K.; Heinze, J. J. Electrochem. Soc. 1999, 146, 32853289. 